\title{
The efficacy of Virkon-S for the control of saprolegniasis in common carp, Cyprinus carpio L
}

\author{
Haitham Saeed Rahman ${ }^{1}{ }^{,}$Tae-Jin Choi ${ }^{\text {Corresp. }}{ }^{2}$ \\ ${ }^{1}$ KOICA-PKNU International Graduate Program Fisheries Science, Pukyong National University, Busan, South Korea \\ 2 Department of Microbiology, Pukyong national university, Busan, South Korea \\ Corresponding Author: Tae-jin Choi \\ Email address: choitj@pknu.ac.kr
}

Background. Saprolegniaparasitica is a fish pathogen that causes severe economic losses worldwide. Virkon-S is a well-known disinfectant known to exhibit antimicrobial activities against bacteria, viruses, and fungi. In this study, we tested the anti-fungal activity of Virkon-S against S. parasitica, the major causal agent of saprolegniasis.

Methods. The lowest concentration of Virkon-S that prevented germination or the visible growth of spores and the percent spore germination were determined using potato dextrose agar plates containing different concentrations of Virkon-S. The cytotoxic effect was evaluated using the Ez-Cytox Cell Viability Assay with epithelioma papulosum cyprini (EPC) cells grown in L-15 medium and acute toxicity tests were carried out with cultured fingerlings of common carp for $96 \mathrm{~h}$. Artificial infection with S. parasitica was performed by placing the fish in tanks containing zoospores of $S$. parasitica after descaling and wounding at three positions. The diseased fish were kept in tanks containing 2, 4, and 10 ppm of Virkon-S for 10 days to observe the treatment effect.

Results. The in vitro assay results showed that Virkon-S could inhibit spore germination and the resulting mycelial growth at a concentration as low as 4 ppm. No cytotoxic effect on EPC cells was observed even at a concentration as high as 100 ppm. Additionally, no acute toxicity in the common carp was observed at 10 ppm following $96 \mathrm{~h}$ exposure. Ten days of treatment with 4 and 10 ppm Virkon-S resulted in complete reversal of artificially-induced saprolegniasis in the common carp.

Discussion. This data indicates that Virkon-S can be used for the control of saprolegniasis without harmful effects in fish. However, further research on the effect in humans and food supplies is necessary. 
1 The efficacy of Virkon-S for the control of saprolegniasis in common carp,

2

3

4

5

6

$10 *$ Corresponding author;

11 Dr. Tae-Jin Choi

12 Email: choitj@pknu.ac.kr

13

14

15

16

17

18

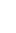

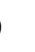

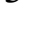

\title{
Cyprinus carpio L.
}

\author{
Haitham Saeed Rahman ${ }^{1}$ and Tae-Jin Choi ${ }^{2, *}$
}

${ }^{1}$ KOICA-PKNU International Graduate Program Fisheries Science, Graduate School of Global Fisheries, and ${ }^{2}$ Department of Microbiology, Pukyong National University, Busan 48513, Korea

*The English in this document has been checked by at least two professional editors, both native speakers of English. For a certificate, please see: http://www.textcheck.com/certificate/JQ8e2t 


\section{Abstract}

21 Background. Saprolegnia parasitica is a fish pathogen that causes severe economic losses

22 worldwide. Virkon-S is a well-known disinfectant known to exhibit antimicrobial activities

23 against bacteria, viruses, and fungi. In this study, we tested the anti-fungal activity of Virkon-S

24 against $S$. parasitica, the major causal agent of saprolegniasis.

25 Methods. The lowest concentration of Virkon-S that prevented germination or the visible growth

26 of spores and the percent spore germination were determined using potato dextrose agar plates

27 containing different concentrations of Virkon-S. The cytotoxic effect was evaluated using the

28 Ez-Cytox Cell Viability Assay with epithelioma papulosum cyprini (EPC) cells grown in L-15

29 medium and acute toxicity tests were carried out with cultured fingerlings of common carp for

$3096 \mathrm{~h}$. Artificial infection with $S$. parasitica was performed by placing the fish in tanks containing

31 spores of $S$. parasitica after descaling and wounding at three positions. The diseased fish were

32 kept in tanks containing 2, 4, and 10 ppm of Virkon-S for 10 days to observe the treatment effect.

33 Results. The in vitro assay results showed that Virkon-S could inhibit spore germination and the

34 resulting mycelial growth at a concentration as low as $4 \mathrm{ppm}$. No cytotoxic effect on EPC cells

35 was observed even at a concentration as high as $100 \mathrm{ppm}$. Additionally, no acute toxicity in the

36 common carp was observed at $10 \mathrm{ppm}$ following $96 \mathrm{~h}$ exposure. Ten days of treatment with 4

37 and 10 ppm Virkon-S resulted in complete reversal of artificially-induced saprolegniasis in the 38 common carp.

39 Discussion. This data indicates that Virkon-S can be used for the control of saprolegniasis

40 without harmful effects in fish. However, further research on the effect in humans and food 41 supplies is necessary. 


\section{Introduction}

44 Fungal infections are one of the main factors of mortality and economic loss among the 45 ornamental and food fish farming industries (Fregeneda-Grandes et al., 2007; Jalilpoor et al., 46 2006). The most common and economically important fungal disease of cultured fish is

47 saprolegniasis. Saprolegniasis, which is also known as 'winter fungus', usually occurs between

48 October and March when the water temperature is below $15^{\circ} \mathrm{C}$, but mortality usually increases as

49 the temperature rises in early spring (Osman et al., 2008). Saprolegnia infections are visible to

50 the naked eye as white patches on the skin of the infected fish or as 'cotton wool' on fish eggs.

51 From these eggs the fungus can spread to live eggs via positive chemotaxis, meaning some

52 chemical signals from the live eggs cause the fungus to move towards them (Bruno and Wood, 53 1999).

The term 'saprolegniasis' describes infection with fungi, actually a phylogenetic lineage of fungus-like microorganisms of the family Saprolegniaceae in the order Saprolegniales of class Oomycota. Two main genera, Saprolegnia and Achlya of the family Saprolegniaceae, can infect fish or shellfish. Although the pathogenic organisms responsible for saprolegniasis have not yet been identified, three species including Saprolegnia parasitica and S. diclina which are taxonomically difficult group and referred as the Saprolegnia complex (Willoughby et al., 1985), and Achlya hoferi are the major etiological agents of this disease, and S. parasitica is known as

61 the most important among them (Van West, 2006). S. parasitica penetrate into epidermal tissues, 62 usually colonizing the tail or head region and then proliferate to cover the entire body surface 63 (Willoughby, 1994). 
65 (Oláh and Farkas, 1978; Srivastava and Srivastava, 1978; Alderman, 1985). However, the

66 compound was banned worldwide in 2002 due to its undesirable effects on animal health (Van

67 West, 2006; Stammati et al., 2005; Srivastava et al., 2004; Brock and Bullis, 2001). Since then, 68 the search for new and effective substances against Saprolegnia infections has intensified. 69 Although chemicals including formalin, hydrogen peroxide, sodium chloride (Rach et al., 2005;

70 Barnes et al., 2003; Schreier et al., 1996), copper sulfate (Straus et al., 2009), detergents such as 71 bronopol (Pottinger and Day, 1999) and ozone (Forneris et al., 2003) have been shown to be 72 somewhat effective, none were as effective as malachite green. The use of these types of 73 compounds has led to a number of problems, including the development of fungicide resistance and potentially harmful effects to human health (Phillips et al., 2008; Stammati et al., 2005). As such, there is still an urgent need to develop new alternatives that are effective in combating mycotic infections, but also safe for fish and the environment (Khosravi et al., 2012).

Virkon-S was originally developed by Antec International (Antec International Limited, Sudbury, Suffolk, UK) and launched in 1986 for use in farming and livestock production. It is regarded as one of the most advanced farm disinfectants. It was one of the first oxidative

80 disinfectants to be used on the farm and continues to lead the way in livestock production and

81 farm biosecurity, having been successfully deployed against 500 disease-causing pathogens

82 including viruses, bacteria, and fungi, which cause foot and mouth disease, avian influenza,

83 Salmonella, and Campylobacter (Marchetti et al., 2006; Hernandez et al., 2000). Due to its wide

84 range of antimicrobial activity and relative safety, Virkon-S is used by the United Nation's Food

85 and Agriculture Organization and governments worldwide to secure biosafety and strengthen

86 Emergency Disease Control Contingency Planning (http://www.virkon.com/en/products-

87 applications/disinfectants/virkon-s/). In Korea, Virkon-S has been approved as a quasi-drug for 
88 animals and was used as a disinfectant for aquaculture facilities in 2016.

89 Despite the wide spectrum of antimicrobial activity of Virkon-S, there have been no

90 reports of its antifungal activity against Saprolegnia. In this study, we tested the antifungal

91 activity of Virkon-S against $S$. parasitica in vitro and in vivo to determine the possibility of using

92 this material for the control of saprolegniasis in the future.

93 The animal protocol used in this study has been reviewed and approved by the Pukyong

94 National-Institutional Animal Care and Use Committee (PKNU-IACUC), which outlines the

95 ethical procedures and scientific care of animals used in studies (Approval Number PKNU-201796 01).

\section{Materials and methods}

Saprolegnia parasitica cultures

S. parasitica was purchased from the Korean Collection for Type Cultures (KCTC 46452) and cultured on potato dextrose agar (PDA) at $25^{\circ} \mathrm{C}$. This strain was isolated from a farmed rainbow trout from an aquaculture farm in Wonju, Gangwondo, Korea in 2016 before deposition.

\section{Fish and rearing conditions}

In total, 100 fingerlings of common carp, Cyprinus carpio, with an average size and weight of $11.5 \pm 1 \mathrm{~cm}$ and $17.6 \pm 3 \mathrm{~g}$, respectively, were obtained from Namsangju Aquaculture Farm,

107 located in Sangju-si, Gyeongsangbuk-do, Korea. Each fish was examined for infection and 108 acclimated in $450-\mathrm{L}$ rearing tanks at $22 \pm 2{ }^{\circ} \mathrm{C}$ for 10 days. During the acclimatization period,

109 fish were fed twice daily with a proper diet according to Ellsaesser et al. (1986). 


\section{Virkon-S}

112 Virkon-S was purchased from Bayer Korean (Seoul, Korea) and $1 \mathrm{~kg}$ contained triple salt

$113500 \mathrm{~g}$, hexametaphosphate $181 \mathrm{~g}$, sodium dodecyl benzene sulphonic acid $150 \mathrm{~g}$, malic acid 100

$114 \mathrm{~g}$, sulphamic acid $50 \mathrm{~g}$, and sodium chloride $15 \mathrm{~g}$. A $10 \%$ stock was prepared with distilled water

115 and further dilutions were made when necessary.

117 Inhibition of spore germination

118 The inhibitory effects of Virkon-S on spore germination were tested using two methods.

119 First, the minimum fungicidal concentration (MFC), defined as the lowest concentration of a

120 chemical that prevents germination or the visible growth of spores, was determined as described

121 previously (Yao et al., 2017; Hu et al., 2013). Spore suspension containing oospores and 122 zoospores was prepared as described as Yao et al. (2017). S. parasitica was cultured on PDA at $12325^{\circ} \mathrm{C}$ for 12 days to induce spores. Approximately $10 \mathrm{ml}$ of distilled water was added to each 87 $124 \mathrm{~mm}$ diameter Petri dish and the mycelium and spores were scraped and filtered through eight 125 layers of sterile cheesecloth. The final concentration of spores was adjusted to approximately $1 \times$ $12610^{6}$ spores/ml using a hemocytometer. A $10 \mu \mathrm{l}$ sample of spore suspension was spotted on the 127 center of a 87-mm diameter Petri dish containing $20 \mathrm{ml}$ of PDA with $0,2,4,10,20$, or 100 ppm 128 Virkon-S, and incubated at $25^{\circ} \mathrm{C}$. After $72 \mathrm{~h}$ of incubation, the diameter of mycelial growth was 129 measured. Inhibition of spore germination was also determined by percent spore germination as 130 described by Kiraly et al. (1974). PDA plates containing 0, 2, 4, 10, 20, and 100 ppm Virkon-S

131 were prepared but the amount of total PDA was only $10 \mathrm{ml}$ for each plate. This condition 132 reduced mycelial growth and the plate was transparent enough to observe spore germination 
133 under a light microscope. Three spots of a $10-\mu 1$ spore suspension were placed on each plate and

134 incubated at $25^{\circ} \mathrm{C}$ for $72 \mathrm{~h}$. The percent spore germination was determined as follows:

135

137 Percent spore germination $=$ $\times 100$

Total no. of spores examined

\section{Mycelial growth inhibition on PDA plates}

Inhibition of $S$. parasitica mycelial growth was tested on PDA plates containing different

142 concentrations of Virkon-S as described by Hu et al. (2013). Briefly, 2× PDA was sterilized,

143 cooled to approximately $65^{\circ} \mathrm{C}$, and mixed with the same volume of Virkon-S to give final

144 Virkon-S concentrations of 2, 4, 10, 20, and $100 \mathrm{ppm} .2 \times$ PDA was mixed with the same volume

145 of sterile water in control plates. Aliquots of the mixture $(10 \mathrm{ml})$ were poured onto $87-\mathrm{mm}$

146 diameter Petri dishes. A Saprolegnia-colonized PDA block of approximately $5 \times 5 \mathrm{~mm}$ was

147 placed on the center of the prepared plates. The plates were incubated at $25^{\circ} \mathrm{C}$ for $72 \mathrm{~h}$ and the

148 diameter of the mycelial growth was measured. The percentage of fungal inhibition was

149 calculated based on the percent inhibition of radial growth (PIRG) as described by Dananjaya et

150 al. (2017) as follows: PIRG $(\%)=[(\mathrm{R} 1-\mathrm{R} 2)] / \mathrm{R} 1 \times 100 \%$, where $\mathrm{R} 1=$ radial growth in control

151 and $\mathrm{R} 2$ = radial growth in treatment.

\section{Cytotoxicity of Virkon-S in epithelioma papulosum cyprini (EPC) cells}

154 The cytotoxic effect of Virkon-S was evaluated using the Ez-Cytox Cell Viability Assay

155 Kit (Dogen-Bio Co., Ltd., Seoul, Korea) with EPC cells by following the procedures described 
156 by Park et al. (2017). EPC cells $\left(1 \times 10^{5}\right)$ were grown in L-15 medium supplemented with $10 \%$

157 fetal bovine serum, penicillin $(62.5 \mu \mathrm{g} / \mathrm{ml})$, and streptomycin $(100 \mu \mathrm{g} / \mathrm{ml})$ in $96-w e l l$ plates

158 overnight. For treatment, the cell medium was replaced with medium (100 $\mu 1)$ containing 10, 100,

$159500,1,000,5000$, and $10,000 \mathrm{ppm}$ of Virkon-S. Non-treated cells were used as a negative

160 control. After $24 \mathrm{~h}$ of incubation, $110 \mu \mathrm{l}$ of medium containing $10 \mu \mathrm{l}$ of water-soluble

161 tetrazolium solution was added to each well, and the plates were incubated for a further $4 \mathrm{~h}$. The

162 absorbance at $460 \mathrm{~nm}$ was measured using an enzyme-linked immunosorbent assay reader

163 (Molecular Devices, Silicon Valley, CA, USA), and relative cell viability was calculated using

164 cells treated with medium only as a control.

165

166 Acute toxicity in common carp

167 Water-only toxicity tests were carried out with cultured fingerlings of the common carp,

168 Cyprinus carpio, using five concentrations of Virkon-S (2, 4, 10, 20, and $100 \mathrm{ppm})$ and three fish

169 per concentration. Healthy and disease-free fish that were not previously exposed to any

170 pollution agents or toxicants were selected based on their activity and external appearance. The

171 fish were acclimated for 7 days at $18^{\circ} \mathrm{C}$ under constant light and feeding with commercial feed.

172 Three fish were placed in a 3-L glass flask containing different concentrations of Virkon-S and

$173 \mathrm{kept}$ for $96 \mathrm{~h}$ in aerated water without any water changes or feeding. Dead fish were removed

174 from the flask to prevent possible deterioration of the water quality. The percentage of fish

175 mortality was calculated for each concentration after $24,48,72$, and $96 \mathrm{~h}$ of exposure. After $96 \mathrm{~h}$

176 of exposure, all of the survivors were transferred to a 50-L tank equipped with aeration and

177 observed for 40 days for any post-exposure effects.

178 


\section{Inhibition of saprolegniasis by Virkon-S}

180 Five groups of 20 fish were used for artificial infection with $S$. parasitica and treatment

181 with Virkon-S. Three groups were artificially infected and treated with 2, 4, and 10 ppm Virkon-

182 S. Fish in the positive control group were infected with S. parasitica but not treated with Virkon-

183 S. Fish in the negative control group were neither infected with $S$. parasitica nor treated with

184 Virkon-S. Fish were kept in a 150-L glass fiber tank separated into three sections with a metal

185 screen with six or seven fish in each section. The water temperature was fixed at $17 \pm 1^{\circ} \mathrm{C}$ using

186 a room air conditioner. All fish were observed for behavioral and clinical signs of infection.

187 For artificial infection with S. parasitica, fish were descaled and wounded in three places

188 on one side of the body (top of the head, center of the body, and the tail region) using a sharp

189 scalpel. The wounded area was approximately $1 \mathrm{~cm}^{2}$. Spores of $S$. parasitica were prepared as

190 above and added to tanks containing the three treatment groups and the positive control group at

191 a final concentration of $1 \times 10^{5}$ spores/ml (Willoughby, 1994; Hatai et al., 1994).

192 Ten days after the addition of spores, white cotton wool-like growth on the surface of the

193 wounded area was observed with a light microscope and cultured on PDA at $25^{\circ} \mathrm{C}$ for 3 days.

194 The morphological and microscopic characteristics of the culture were compared with the

195 characteristics of $S$. parasitica recorded from previous studies (Hatai et al., 1990; Willoughby et

196 al., 1984). Virkon-S solution was added to these treatment tanks at final concentrations of 2, 4,

197 and $10 \mathrm{ppm}$ to assess the treatment effect. The water in the tank was replaced with the same

198 concentration of Virkon-S after 5 days and the cumulative mortality was recorded for 10 days.

199 The fish were diagnosed by clinical signs and lesion healing 10 days after treatment.

\section{Results}




\section{Inhibition of spore germination}

203 The inhibition of S. parasitica spore germination by Virkon-S was tested by observing the

204 mycelial growth from a suspension of spores on PDA plates of normal thickness (20 ml media in

205 87-mm plates) and enumerating spore germination on PDA plates of half thickness. There was

206 no sign of mycelial growth on plates containing 4, 10, 20, and 100 ppm Virkon-S $72 \mathrm{~h}$ after

207 incubation at $25^{\circ} \mathrm{C}$ (Fig. 1A-D). Mycelial growth on a plate containing $2 \mathrm{ppm}$ was $53.8 \%$ of the 208 control plate (35 vs. $65 \mathrm{~mm}$, respectively) (Fig. 1E). Therefore, MFC was defined as less than or 209 equal to 4 ppm on PDA plates.

210 There was no sign of spore germination on plates of half thickness containing $4,10,20$, or

$211100 \mathrm{ppm}$ Virkon-S $72 \mathrm{~h}$ after incubation at $25^{\circ} \mathrm{C}$. A small number of spores on PDA plates 212 containing 2 ppm germinated at a rate of 39.2\% (22 out of 56) (Fig. 2C). In contrast, most of the

213 spores on control plates germinated at a rate of $96.2 \%$ (51 out of 53 spores). Therefore, the 214 inhibition rate of spore germination was calculated as $59 \%$ at a concentration of 2 ppm [(96.2$21539.2) / 96.2 \times 100]$.

216

217 Mycelia growth inhibition

218 The growth of $S$. parasitica on PDA containing 2, 4, 10, 20, and 100 ppm Virkon-S was

219 observed after inoculation at $25^{\circ} \mathrm{C}$ for $72 \mathrm{~h}$. No growth of mycelia was observed in the plates 220 containing 10, 20, and 100 ppm Virkon-S (Fig. 2A-C). There was slight growth of S. parasitica 221 on PDA plates containing 4 ppm Virkon-S (Fig. 2D). The growth inhibition rate (IR) on plates 222 containing 4 and 2 ppm was 69.2 and $25.6 \%$, respectively when the IR was calculated as [\% IR = $223100-100 \mathrm{X} / \mathrm{Y}]$, where $\mathrm{X}=$ mycelia growth in sample; $\mathrm{Y}=$ mycelia growth in control. 


\section{Cytotoxicity of Virkon-S in cultured EPC cells}

The cytotoxic effect of Virkon-S in EPC cells is shown in Figure 3. There was no effect of

227

228

229

230

231

232

233

234

235

236

237

238

239

240

241

242

243

Virkon-S on cell viability at 10 and $100 \mathrm{ppm}$. There was a slight decrease (97\%) at $500 \mathrm{ppm}$. However, the cell viability dropped suddenly when the Virkon-S concentration was greater than 1,000 ppm. In the mycelial growth inhibition and spore germination inhibition assays, 4 ppm was enough to inhibit spore germination and the resulting mycelial growth. Even a concentration of $100 \mathrm{ppm}$ did not result in any toxicity in EPC cells. Therefore, $10 \mathrm{ppm}$ and lower concentrations were used in further experiments.

\section{Acute toxicity test of Virkon-S in common carp}

Acute toxicity of Virkon-S in common carp was investigated by placing fish in glass flasks containing five different concentrations of Virkon-S for up to $96 \mathrm{~h}$. As shown in Table 1, all fish in the 100-ppm flask died within $24 \mathrm{~h}$. Moreover, 75 and 100\% cumulative mortality was observed within 24 and 46 h, respectively, in the 20-ppm flask. However, no mortality was observed in the flasks containing 10, 4, and 2 ppm Virkon-S. Furthermore, the survivors from the acute toxicity test did not show any after-exposure effects when they were kept in a culture tank for 40 days. Therefore, it was concluded that $10 \mathrm{ppm}$, which inhibited spore germination and mycelial growth, did not cause any cytotoxic effects in EPC cells, and therefore can be defined as the maximum acceptable toxicant concentration (MATC) for Virkon-S.

\section{Induction of artificial infection and treatment with Virkon-S}



wounded common carp, the typical signs of saprolegniasis, including cotton shape growth of 248 fungi and wound ulceration, appeared (Fig. 4A). The cotton wool-like mycelial growth was 249 removed from the wound and observed with a microscope to confirm its resemblance to the inoculated $S$. 250 parasitica, and placed on a PDA plate to induce mycelial growth. Both the cotton wool-like mycelial

251 growth from the infected fish and mycelia grown on the PDA plate showed the same morphological

252 characteristics of $S$. parasitica, which indicated that the disease was induced by the spores of S. parasitica 253 that had been added to the tanks. The diseased fish were treated with Virkon-S at a final concentration of 2542 , 4, and $10 \mathrm{ppm}$ and the results are shown in Table 2. During the 10-day treatment period, no mortality 255 was observed among fish treated with 4 and $10 \mathrm{ppm}$. However, the cumulative mortality in the 2-ppm 256 tank reached 50\%. Furthermore, fish treated with 4 and $10 \mathrm{ppm}$ showed clear recovery from the disease.

257 As shown in Figure 4B, all of the cotton shape fungal growth disappeared from the body of the fish.

258 Furthermore, new scales appeared and covered the wounded area, which indicated complete recovery 259 from the disease.

\section{Discussion}

Since malachite green has been banned for the treatment of saprolegniasis due to possible genotoxicity, carcinogenetic effects, and residual toxicity, this disease has resulted in severe economic losses in the fresh water fish farming industry (Van West, 2006). Although many alternatives have been tried, no chemicals are presently available that provide sufficient protection against the disease. In addition, sanitary problems, environmental restrictions, and

267 high cost have also limited the use of these synthetic antimicrobials (Yao et al., 2010). The only U.S. Food and Drug Administration-approved compounds for fungus control are 37\% formalin and $35 \%$ hydrogen peroxide, but the efficiency is lower than that of malachite green (Straus et al., 
270 2016).

271 Virkon-S is a well-known disinfectant that has been proven to be effective against bacteria,

272 viruses, and fungi (Gehan et al., 2009). In this study, we showed that Virkon-S has antifungal

273 activity against $S$. parasitica in vitro and in vivo, and to the best of our knowledge, this is the first

274 time this activity has been demonstrated.

275 The minimum concentration for inhibition of spore germination and the resulting mycelial 276 growth on PDA plates was as low as 4 ppm, and partial (53.8\%) inhibition was observed on a

277 PDA plate containing 2 ppm Virkon-S. Therefore, the MFC was determined to be 4 ppm on PDA

278 plates. When the inhibition of spore germination experiment was repeated on thin PDA plates for

279 enumeration, complete spore germination inhibition still occurred at $4 \mathrm{ppm}$ and 59\% inhibition at

$2802 \mathrm{ppm}$ was obtained. Although a concentration of Virkon-S as low as 4 ppm was proven to be

281 effective to inhibit germination in our experiment, the concentration and contact time required

282 for fungi inactivation seems to be specific to each fungus. It has been reported that 1 min of

283 contact with 1\% Virkon-S is sufficient to inactivate Batrachochytrium dendrobatidis, which

284 causes the mass mortality of various amphibian species (Gold et al., 2013; Johnson et al., 2003).

285 On the contrary, Gehan et al. (2009) reported that Aspergillus fumigatus and Fusarium species

286 were resistant to $1 \%$ Virkon-S solution following $30 \mathrm{~min}$ and even $60 \mathrm{~min}$ of contact in the 287 presence of organic materials.

288 Similarly, Rogawansamy et al. (2015) reported that a 10\% concentration of Virkon-S

289 resulted in a mean inhibition zone diameter of only $19.25 \mathrm{~mm}( \pm 7.08)$ for A. fumigatus, and

$29018.67 \mathrm{~mm}( \pm 1.15)$ for Penicillium chrysogenum. Furthermore, 5, 3, and 1\% Virkon-S had no

291 effect on the growth of either fungi. Therefore, it seems that the anti-fungal effect of Virkon-S

292 against each target fungus needs to be tested for practical application of Virkon-S. 
To use Virkon-S for the control of saprolegniasis, it should be safe for fish or treated

294 embryos. The cytotoxicity of Virkon-S was tested with EPC cells, which originated from the

295 fathead minnow, Pimephales promelas. No cytotoxic effect was observed at 10 and 100 ppm,

296 although there was a slight decrease in cell viability (97\%) at 500 ppm (Fig. 3). There have been

297 no reports of the cytotoxicity of Virkon-S in cultured fish cell lines. However, its ability to

298 inactivate animal viruses has been tested on animal cells. For example, We et al. (2017) reported

299 that the cytotoxicity of 1\% Virkon-S on cultured baby hamster kidney 21 A cells was completely

300 abolished at a 1 in 81 dilution (123 ppm) in cell culture media, which is similar to our data and

301 significantly lower than the recommended $1 \%$ concentration for use as a disinfectant.

302 Our results indicated that 4 ppm was sufficient to inhibit spore germination and mycelial

303 growth. Therefore, it seems that Virkon-S could be used to control the growth of S. parasitica

304 without any cytotoxic effects at a concentration that can inhibit the fungus. This was further

305 confirmed by acute toxicity tests. No toxic effect was observed in fish kept at 2, 4, and $10 \mathrm{ppm}$

306 for $96 \mathrm{~h}$ (Table 2). Moreover, these fish did not show any after-exposure effects up to 40 days

307 after termination of the test. Considering the results from all of the experiments, the MATC was

308 determined to be $10 \mathrm{ppm}$.

309 The efficacy of Virkon-S was tested with fish that were artificially infected with $S$.

310 parasitica. Fish that were wounded and inoculated with $S$. parasitica spores showed clear

311 symptoms of saprolegniasis 10 days after inoculation, which was confirmed by microscopic

312 observation and colony morphology on PDA plates. Fish treated with 2, 4, and 10 ppm Virkon-S

313 showed 50, 100 and 100\% disease recovery, respectively after 10 days of treatment. The

314 concentrations required for the control of the disease coincided with the concentrations obtained 
315 from the in vitro assay. In addition to $100 \%$ survival of the treated fish, all recovered fish showed

316 regeneration of scales on the wounded area, which is an indication of successful treatment.

317

318 Conclusions

Virkon-S is approved as a quasi-drug that can be used as a disinfectant for the treatment of

320

aquaculture facilities and equipment in Korea. The results of this study indicate that $4 \mathrm{ppm}$ of

321 Virkon-S can also be used for the control of saprolegniasis with no toxic effects on cultured fish

322 cells or fish in tanks. Although further research on the effect in humans is necessary, Virkon-S is

323 a good candidate for the control of saprolegniasis, which causes huge economic losses in the

324 aquaculture industry.

326

327

328

329

330

331

332

333

334

335

336

337

338

339

340

341

342

343

344

345

346

\section{References}

Alderman, D. J. (1985). Malachite green: a review. Journal of Fish Diseases 8:289-298. DOI: 10.1111/j.1365-2761.1985.tb00945.x.

Barnes, M. E., Stephenson, H., \& Gabel, M. (2003). Use of hydrogen peroxide and formalin treatments during incubation of landlocked fall Chinook salmon eyed eggs. North American Journal of Aquaculture 65:151-154. DOI: 10.1577/15488454(2003)65<151:UOHPAF>2.0.CO;2.

Brock JA, Bullis R. 2001. Disease prevention and control for gametes and embryos of fish and marine shrimp. In: lee CS, Donaldson EM, ed. Reproductive Biotechnology in Finfish Aquaculture Amsterdam: Elsevier, 137-159. DOI: 10.1016/B978-0-444-50913-0.50010-2.

Bruno DW, Wood BP. 1999. Saprolegnia and other oomycetes. In: Woo PTK, Bruno DW, Diseases and disorders, Viral, Bacterial and Fungal infections. Wallingford: CAB International, 599-653.

Dananjaya SHS, Udayangani RMC, Shin SY, Edussuriya M, Nikapitiya C, Lee J, De Zoysa M. 2017. In vitro and in vivo antifungal efficacy of plant based lawsone against Fusarium oxysporum species complex. Microbiological research 201:21-29. DOI: 10.1016/j.micres.2017.04.011. 
347

348

349

350

351

352

353

354

355

356

357

358

359

360

361

362

363

364

365

366

367

368

369

370

371

372

373

374

375

376

377

378

379

380

381

382

383

384

385

386

387

388

389

390

391

392
Ellsaesser CF, Clem LW. 1986. Haematological and immunological changes in channel catfish stressed by handling and transport. Journal of Fish Biology 28:511-521. DOI: 10.1111/j.1095-8649.1986.tb05187.x.

Forneris G, Bellardi S, Palmegiano GB, Saroglia M, Sicuro B, Gasco L, Zoccarato I. 2003. The use of ozone in trout hatchery to reduce saprolegniasis incidence. Aquaculture 221:157-166. DOI: 10.1016/S0044-8486(02)00518-5.

Fregeneda-Grandes JM, Rodríguez-Cadenas F, Aller-Gancedo J M. 2007. Fungi isolated from cultured eggs, alevins and brood fish of brown trout in a hatchery affected by saprolegniosis. Journal of Fish Biology 71:510-518. DOI: 10.1111/j.10958649.2007.01510.x.

Gehan ZM, Anwer W, Amer HM, El-Sabagh IM, Rezk A, Badawy EM. 2009. In vitro efficacy comparisons of disinfectants used in the commercial poultry farms. International Journal of Poultry Science 8:237-41.

Gold KK, Reed PD, Bemis DA, Miller DL, Gray MJ, Souza MJ. 2013. Efficacy of common disinfectants and terbinafine in inactivating the growth of Batrachochytrium dendrobatidis in culture. Diseases of aquatic organisms 107:77-81. DOI: 10.3354/dao02670.

Hatai K. 1994. Pathogenicity of Saprolegnia parasitica coker. Salmon saprolegniasis, 87-98.

Hatai K, Willoughby LG, Beakes GW. 1990. Some characteristics of Saprolegnia obtained from fish hatcheries in Japan. Mycological Research 94:182-190. DOI: 10.1016/S09537562(09)80611-4.

Hernndez A, Martro E, Matas L, Martın M, Ausina V. 2000. Assessment of in-vitro efficacy of $1 \%$ Virkon ${ }^{\circledR}$ against bacteria, fungi, viruses and spores by means of AFNOR guidelines. Journal of Hospital Infection 46:203-209. DOI: 10.1053/jhin.2000.0818. DOI: $10.1111 /$ jwas. 12052 .

$\mathrm{Hu}$ XG, Liu L, Hu K, Yang XL, Wang GX. 2013. In vitro screening of fungicidal chemicals for antifungal activity against Saprolegnia. Journal of the world aquaculture society 44:528535. DOI: $10.1111 /$ jwas. 12052

Jalilpoor J, Shenavar Masouleh A, Masoumzadeh M. 2006. Fungal flora in Acipenser persicus eggs with particular emphasis on Saprolegnia sp.(Oomycetes) and mortality during mass incubation at the Shahid Beheshti hatchery. Journal of Applied Ichthyology 22:265-268. DOI: 10.1111/j.1439-0426.2007.00965.x.

Johnson ML, Berger L, Phillips L, Speare R. 2003. Fungicidal effects of chemical disinfectants, UV light, desiccation and heat on the amphibian chytrid, Batrachochytrium dendrobatidis. Diseases of aquatic organisms 57:255-260. DOI: 10.3354/dao057255. 
393

394

395

396

397

398

399

400

401

402

403

404

405

406

407

408

409

410

411

412

413

414

415

416

417

418

419

420

421

422

423

424

425

426

427

428

429

430

431

432

433

434

435

436

437

438

Khosravi AR, Shokri H, Sharifrohani M, Mousavi HE, Moosavi Z. 2012. Evaluation of the antifungal activity of Zataria multiflora, Geranium herbarium, and Eucalyptus camaldolensis essential oils on Saprolegnia parasitica-infected rainbow trout (Oncorhynchus mykiss) eggs. Foodborne pathogens and disease 9:674-679. DOI: 10.1089/fpd.2011.1086

Király Z, Klement Z, Solymosy F, Voros J. 1974. Methods in plant pathology with special reference to breeding for disease resistance. Budapest: Akademia Kiada.

Marchetti V, Mancianti F, Cardini G, Luchetti E. 2006. Evaluation of fungicidal efficacy of benzalkonium chloride (Steramina G uv) and Virkon-S against Microsporum canis for environmental disinfection. Veterinary research communications 30:255-261. DOI: $10.1007 / \mathrm{s} 11259-006-3199-2$

Matheron ME, Porchas M. 2000. Impact of azoxystrobin, dimethomorph, fluazinam, fosetyl-Al, and metalaxyl on growth, sporulation, and zoospore cyst germination of three Phytophthora spp. Plant Disease 84:454-458. DOI: 10.1094/PDIS.2000.84.4.454.

Oláh J, Farkas J. 1978. Effect of temperature, pH, antibiotics, formalin and malachite green on the growth and survival of Saprolegnia and Achlya parastic on fish. Aquaculture 13:273288. DOI: 10.1016/0044-8486(78)90009-1.

Osman HM, Solman WE, Noor EL, Deen AE, Laila AM. 2008. Induction of saprolegniosis in Oreochromis niloticus with special reference to its Biological Control. Global veterinaria, 2:32-37.

Park YJ, Moon C, Kang JH, Choi TJ. 2017. Antiviral effects of extracts from Celosia cristata and Raphanus sativus roots against viral hemorrhagic septicemia virus. Archives of virology, 162:1711-1716. DOI: 10.1007/s00705-017-3270-z.

Phillips AJ, Anderson VL, Robertson EJ, Secombes CJ, Van West P. 2008. New insights into animal pathogenic oomycetes. Trends in microbiology, 16:13-19. DOI: 10.1016/j.tim.2007.10.013.

Pottinger TG, Day JG. 1999. A Saprolegnia parasitica challenge system for rainbow trout: assessment of Pyceze as an anti-fungal agent for both fish and ova. Diseases of Aquatic Organisms, 36:129-141. DOI: 10.3354/dao036129.

Rach JJ, Redman S, Bast D, Gaikowski MP. 2005. Efficacy of hydrogen peroxide versus formalin treatments to control mortality associated with saprolegniasis on lake trout eggs. North American Journal of Aquaculture, 67:148-154. DOI: 10.1577/A04-062.1.

Rogawansamy S, Gaskin S, Taylor M, Pisaniello D. 2015. An evaluation of antifungal agents for the treatment of fungal contamination in indoor air environments. International journal of environmental research and public health, 12:6319-6332. DOI: 10.3390/ijerph120606319. 
439

440

441

442

443

444

445

446

447

448

449

450

451

452

453

454

455

456

457

458

459

460

461

462

463

464

465

466

467

468

469

470

471

472

473

474

475

476

477

478

479

Schreier TM, Rach JJ, Howe GE. 1996. Efficacy of formalin, hydrogen peroxide, and sodium chloride on fungal-infected rainbow trout eggs. Aquaculture, 140:323-331. DOI: 10.1016/0044-8486(95)01182-X.

Srivastava GC, Srivastava RC. 1978. A note on the potential applicability of malachite green oxalate in combating fish-mycoses. Mycopathologia, 64:169-171. DOI: 10.1007/BF00576369.

Srivastava S, Sinha R, Roy D. 2004. Toxicological effects of malachite green. Aquatic toxicology, 66:319-329. DOI: 10.1016/j.aquatox.2003.09.008.

Stammati A, Nebbia C, De Angelis I, Albo AG, Carletti M, Rebecchi C, Dacasto M. 2005. Effects of malachite green (MG) and its major metabolite, leucomalachite green (LMG), in two human cell lines. Toxicology in vitro, 19:853-858. DOI: 10.1016/j.tiv.2005.06.021.

Straus DL, Farmer BD, Ledbetter CK, Beck BH, Williams RS, Clark ML, Freeze TM. 2016. Use of copper sulfate to control egg saprolegniasis at a commercial sunshine bass hatchery. North American journal of aquaculture, 78:243-250. DOI: 10.1080/15222055.2016.1146183.

Straus DL, Mitchell AJ, Carter RR, Steeby JA. 2009. Optimizing copper sulfate treatments for fungus control on channel catfish eggs. Journal of Aquatic Animal Health, 21:91-97. DOI: 10.1577/H07057.1

Van West P. 2006. Saprolegnia parasitica, an oomycete pathogen with a fishy appetite: new challenges for an old problem. Mycologist, 20:99-104. DOI: 10.1016/j.mycol.2006.06.004.

Willoughby LG. 1994. Fungi and fish diseases. Stirling: Pisces Press.

Willoughby LG, Pickering AD, Johnson HG. 1984. Polycell-gel assay of water for spores of Saprolegniaceae (fungi), especially those of the Saprolegnia pathogen of fish. Hydrobiologia, 114:237-248. DOI: 10.1007/BF00031875

Wu G, Selden D, Fooks AR, Banyard A. 2017. Inactivation of rabies virus. Journal of virological methods, 243:109-112. DOI: 10.1016/j.jviromet.2017.02.002

Yao JY, Lin LY, Yuan XM, Ying WL, Xu Y, Pan XY, Ha GH, Shen JY, Wu JC, Ye T, Ge PH. 2017. Antifungal Activity of Rhein and Aloe-Emodin from Rheum palmatum on Fish Pathogenic Saprolegnia sp. Journal of the world aquaculture society, 48:137-144. DOI: 10.1111/jwas.12325

Yao JY, Shen JY, Li XL, Xu Y, Hao GJ, Pan XY, Wnag GX, Yin WL. 2010. Effect of sanguinarine from the leaves of Macleaya cordata against Ichthyophthirius multifiliis in grass carp (Ctenopharyngodon idella). Parasitology research, 107:1035-1042. DOI: 10.1007/s00436-010-1966-z 


\section{Table 1 (on next page)}

Cumulative mortality of common carp during acute exposure to Virkon-S 
1 Table 1. Cumulative mortality of common carp during acute exposure to Virkon-S

\begin{tabular}{ccccc}
\hline \multirow{2}{*}{$\begin{array}{c}\text { Concentration } \\
(\mathrm{ppm})\end{array}$} & \multicolumn{5}{c}{ Cumulative Mortality (\%) } \\
\cline { 2 - 5 } & $24 \mathrm{~h}$ & $48 \mathrm{~h}$ & $72 \mathrm{~h}$ & $96 \mathrm{~h}$ \\
\hline 100 & 100 & - & - & - \\
20 & 75 & 100 & - & - \\
10 & 0 & 0 & 0 & 0 \\
4 & 0 & 0 & 0 & 0 \\
& & & & 0 \\
\hline
\end{tabular}

2 


\section{Table 2 (on next page)}

Healing of artificially induced saprolegniasis by Virkon-S treatment. 
1 Table 1. Cumulative mortality of common carp during acute exposure to Virkon-S

\begin{tabular}{ccccc}
\hline \multirow{2}{*}{$\begin{array}{c}\text { Concentration } \\
(\mathrm{ppm})\end{array}$} & \multicolumn{5}{c}{ Cumulative Mortality (\%) } \\
\cline { 2 - 5 } & $24 \mathrm{~h}$ & $48 \mathrm{~h}$ & $72 \mathrm{~h}$ & $96 \mathrm{~h}$ \\
\hline 100 & 100 & - & - & - \\
20 & 75 & 100 & - & - \\
10 & 0 & 0 & 0 & 0 \\
4 & 0 & 0 & 0 & 0 \\
\hline & 0 & 0 & 0 & 0 \\
\hline
\end{tabular}

2

3 
4 Table 2. Healing of artificially induced saprolegniasis by Virkon-S treatment

Treated concentration $(\mathrm{ppm}) \quad \%$ of healing after treatment $\quad$ Cumulative mortality $(\%)$

\begin{tabular}{ccc}
\hline 10 & 100 & 0 \\
4 & 100 & 0 \\
2 & 50 & 0 \\
Positive control* & 0 & 90 \\
Negative control** & - & 0 \\
\hline
\end{tabular}

5

6 *Positive control group was artificially infected with S. parasitica spores but was not treated with Virkon$7 \mathrm{~S}$

$8 * *$ There was neither artificial infection nor treatment with Virkon-S.

9 


\section{Figure 1}

Inhibition of spore germination and the resulting mycelial growth on potato dextrose agar (PDA) plates using different concentrations of Virkon-S.

The images were taken $72 \mathrm{~h}$ after incubation at $25^{\circ} \mathrm{C}$. A; 100 ppm, B; 20 ppm, C; 10 ppm, D;

4 ppm, and E; 2 ppm. No Virkon-S was added in the control plate. Photo was taken by the first author.

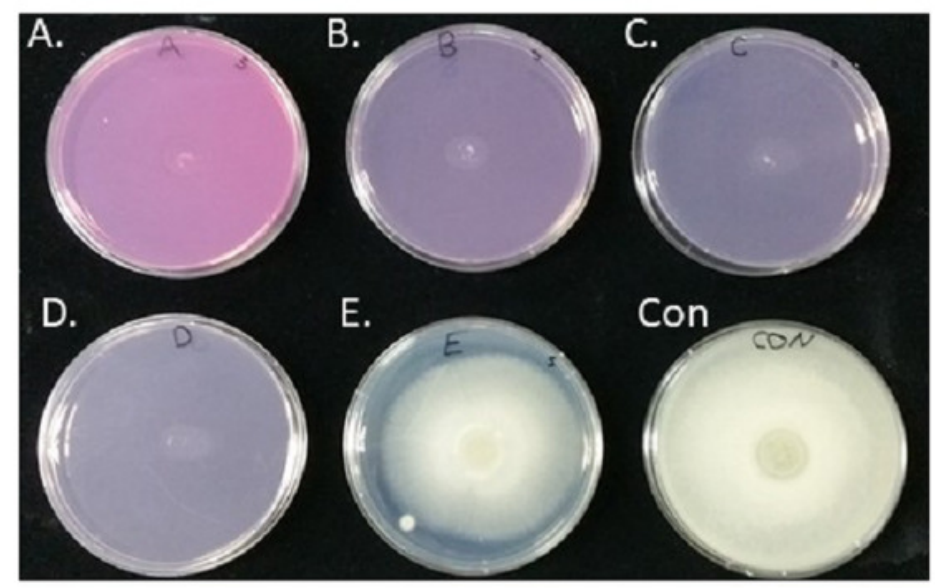




\section{Figure 2}

Inhibition of Saprolegnia parasitica m ycelia growth on PDA plates containing different concentrations of Virkon-S.

A; 100 ppm, B; 20 ppm, C; 10 ppm, D; 4 ppm, and E; 2 ppm. No Virkon-S was added in the control plate. Photo was taken by the first author.

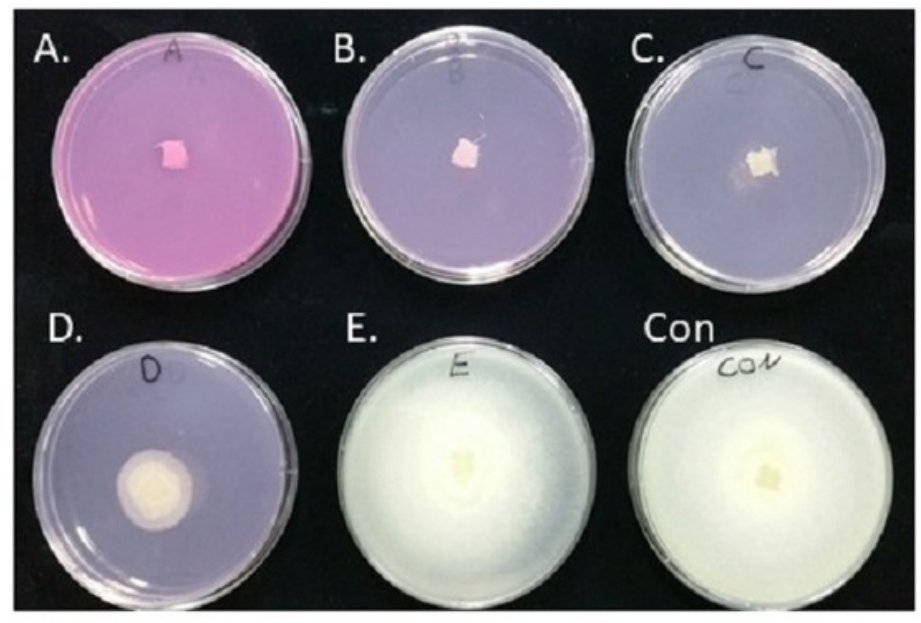


Figure 3

Cytotoxic effect of Virkon-S on cultured epithelioma papulosum cyprini cells.

The results represent the average of eight replications and the standard deviations are indicated.

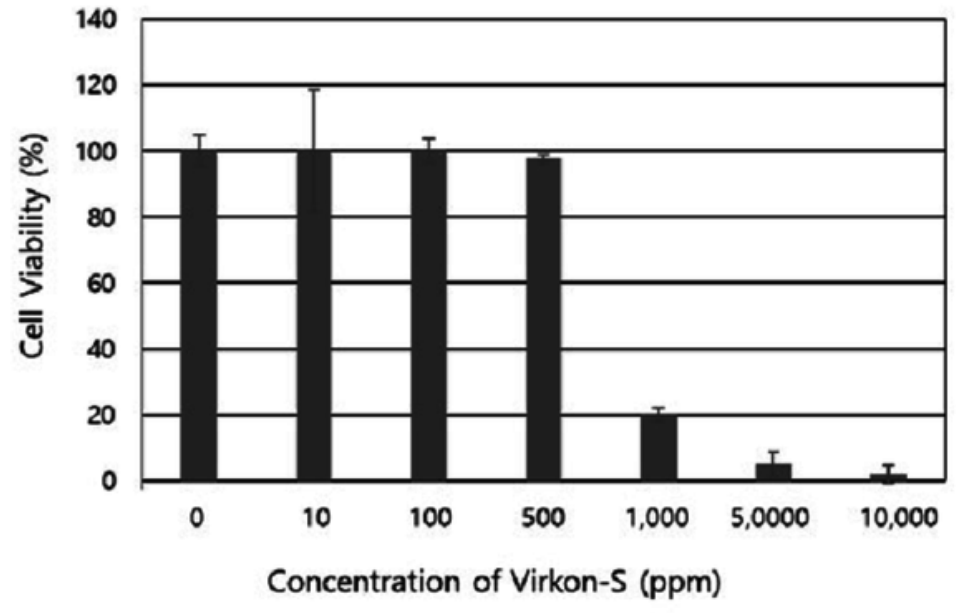




\section{Figure 4}

Artificial induction of saprolegniasis in common carp and treatment with Virkon-S.

A; Clinical signs of $S$. parasitica on the fish body 10 days after artificial wound induction and exposure to the fungal zoospore. B; Recovery from saprolegniasis after treatment for 10 days with 10 ppm Virkon-S. The rectangles indicate the wounded area for artificial infection and show complete recovery from the disease. Scale bars indicate $1 \mathrm{~cm}$. Photos were taken by the first author.

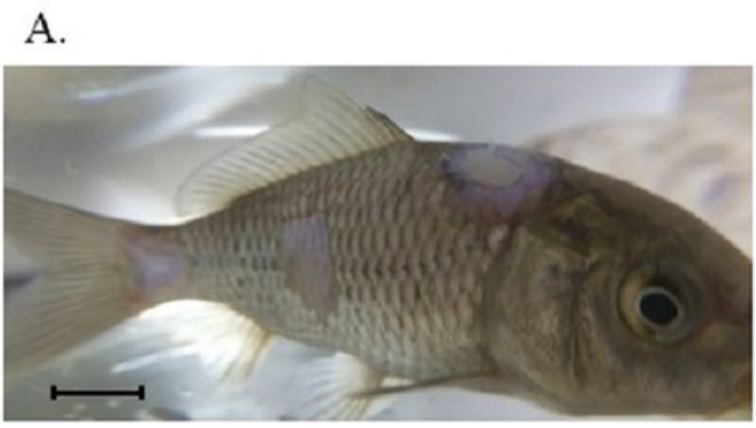

B.

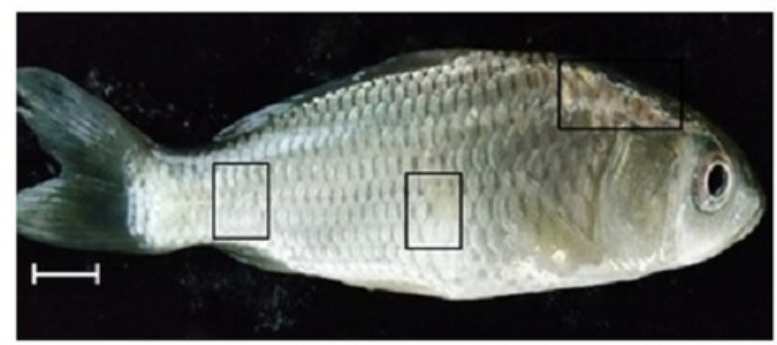

